\title{
Gold Nanoparticle-Based Colorimetric Sensor Array for Discrimination of Organophosphate Pesticides
}

\author{
Nafiseh Fahimi-Kashani ${ }^{\dagger}$, M. Reza Hormozi-Nezhad ${ }^{*+, t}$ \\ tDepartment of Chemistry, Sharif University of Technology, Tehran 11155-9516, Iran \\ Institute of Nanoscience and Nanotechnology, Sharif University of Technology, Tehran, Iran
}


Figure S1

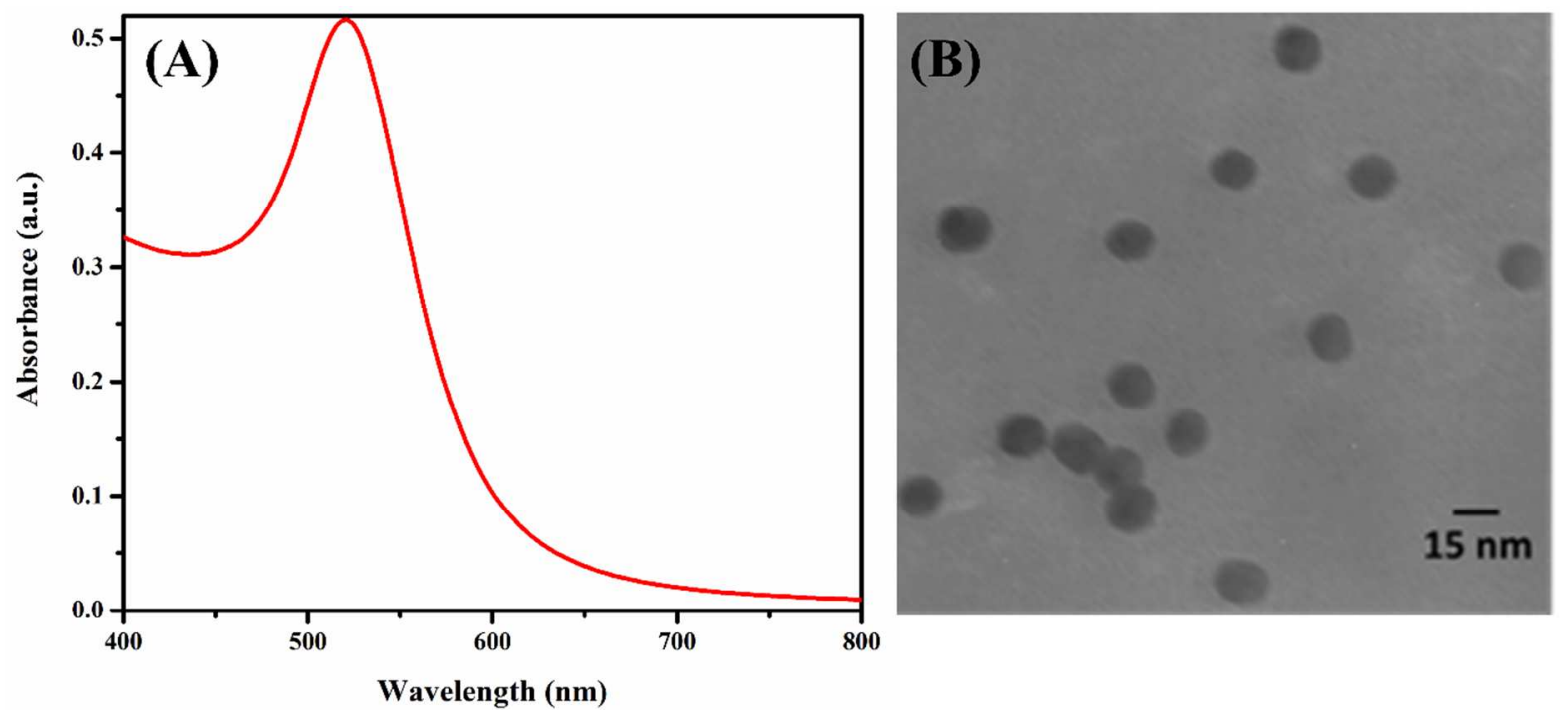

Figure S1 (A) UV-Vis Spectrum and (B) TEM image of as-prepared AuNPs 
Figure S2
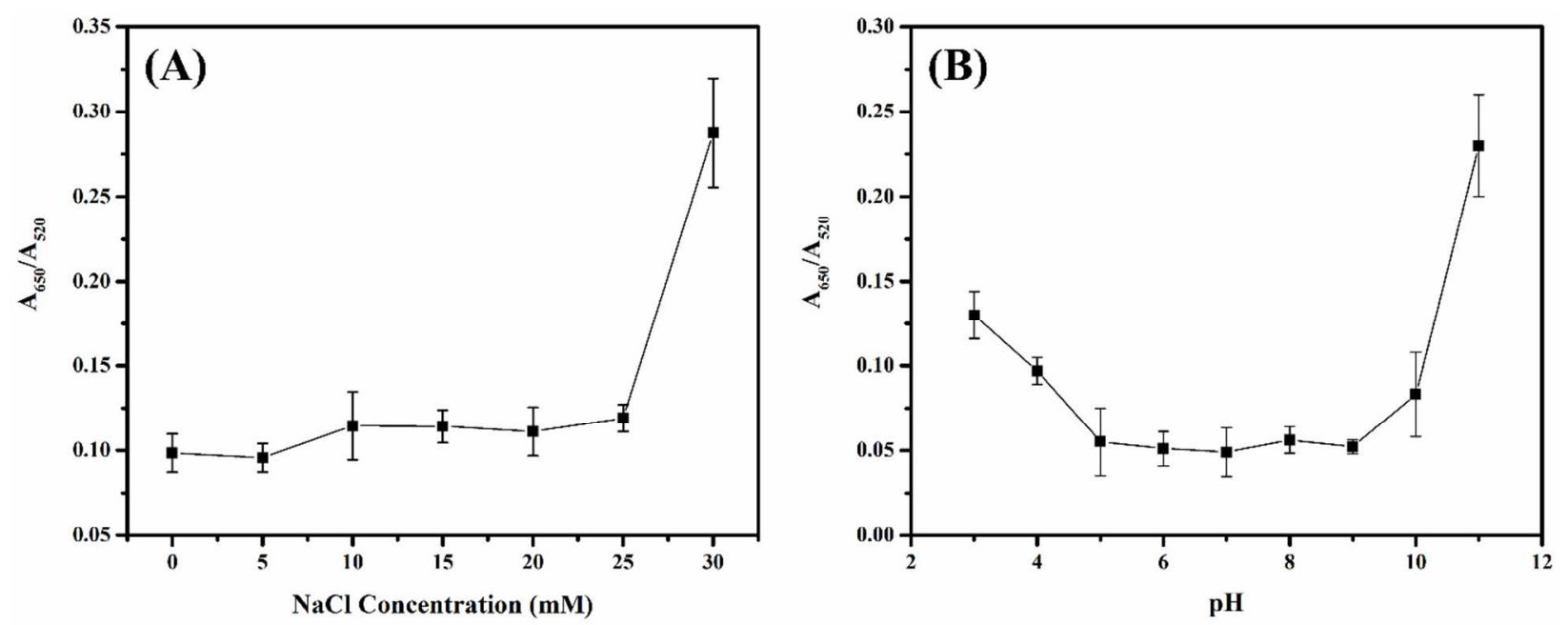

Figure S2 Effect of (A) NaCl Concentration and (B) $\mathrm{pH}$ on Stability of AuNPs. 
Figure S3

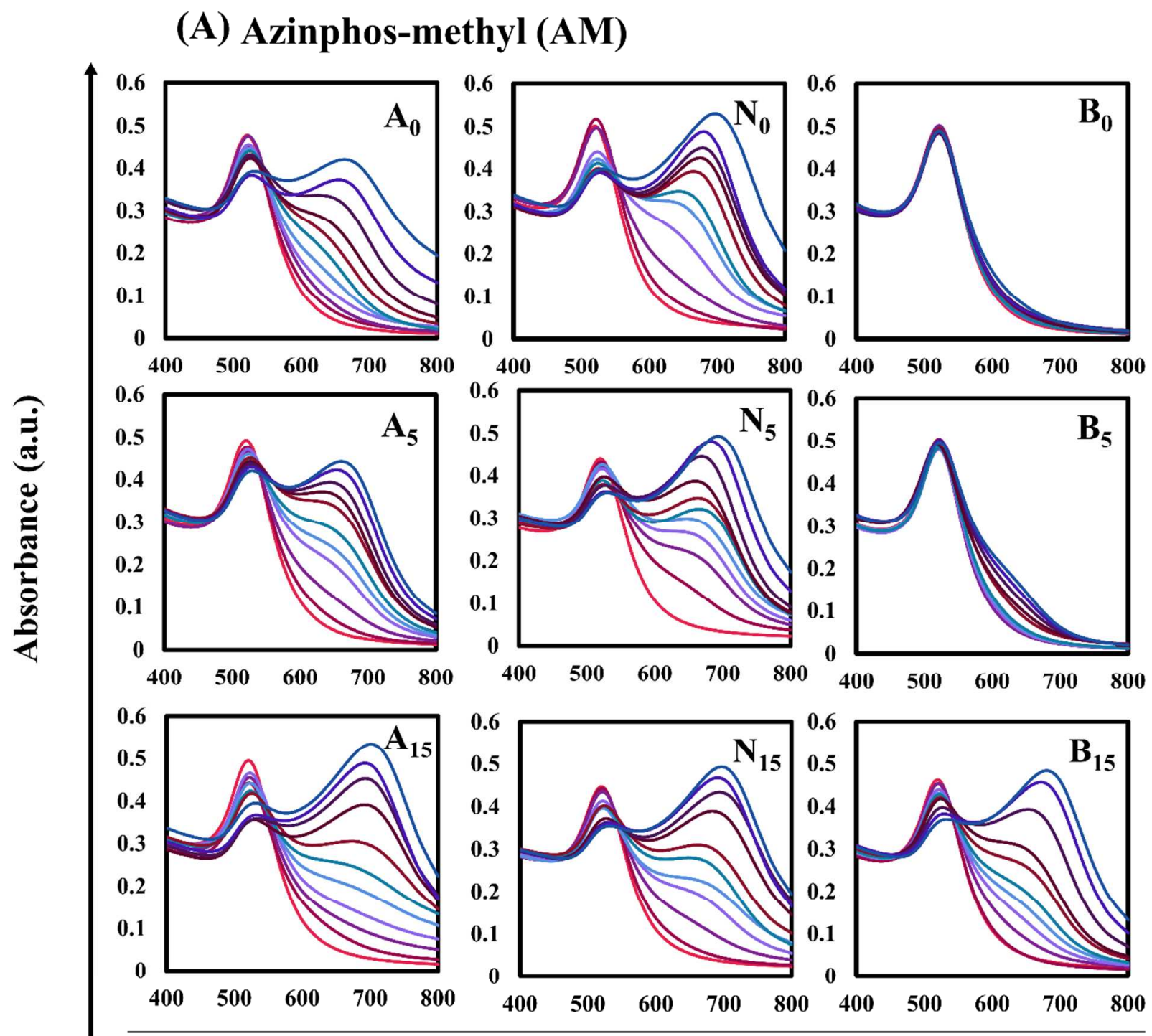

— 40 ng.mL $L^{-1}-80$ ng.mL $L^{-1}-120$ ng.mL $L^{-1}-160$ ng.mL $L^{-1}-200$ ng.mL $L^{-1}$

- 240 ng.mL $L^{-1}-280$ ng.mL $L^{-1}-320$ ng.mL $L^{-1}-360$ ng.mL $L^{-1}-400$ ng.mL $L^{-1}$

Wavelength (nm) 
(B) Chlorpyrifos (CP)

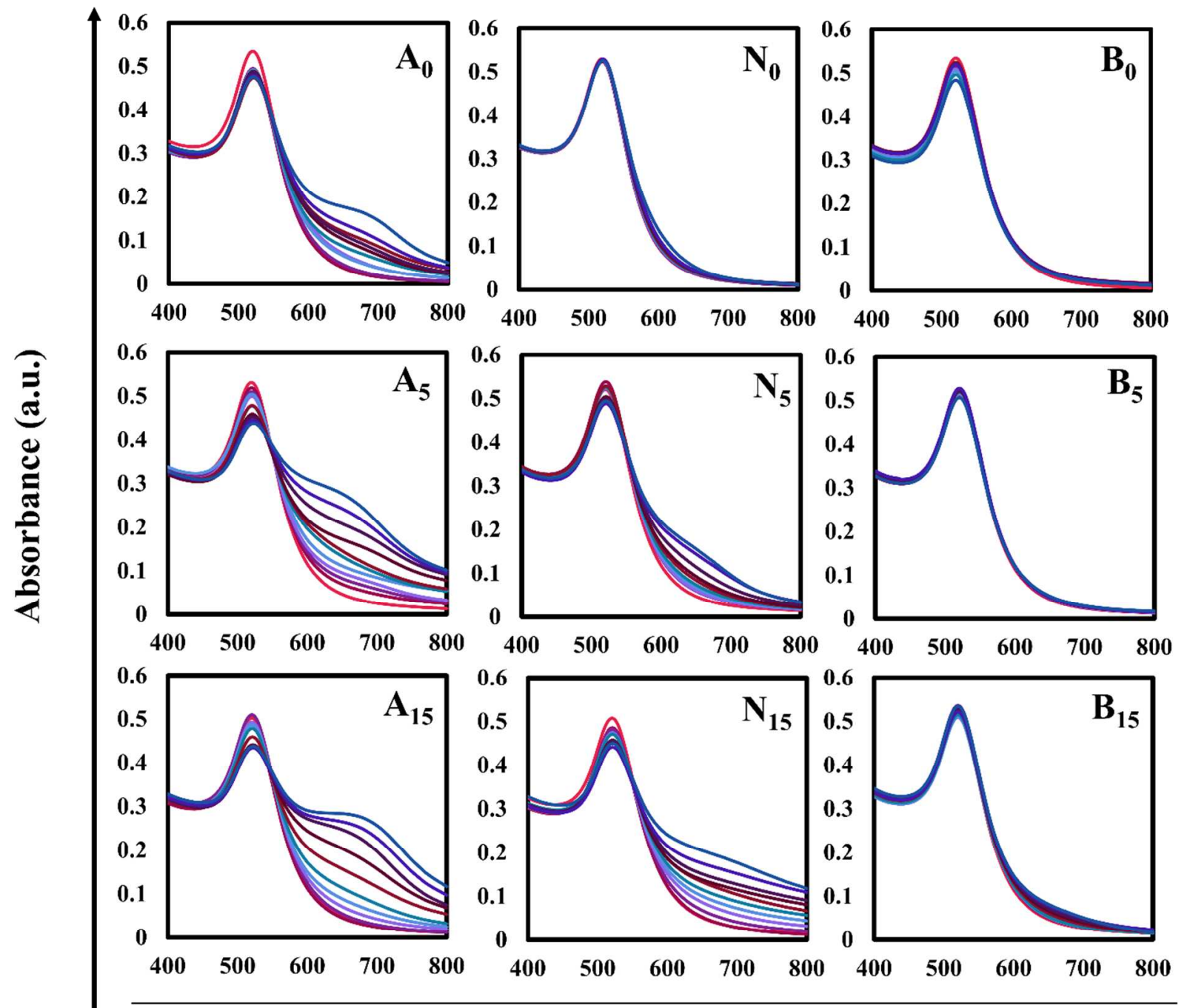

- Blank

- $40 \mathrm{ng} \cdot \mathrm{mL}^{-1}-80 \mathrm{ng} \cdot \mathrm{mL}^{-1}-120 \mathrm{ng} \cdot \mathrm{mL}^{-1}-160 \mathrm{ng} \cdot \mathrm{mL}^{-1}-200 \mathrm{ng} \cdot \mathrm{mL}^{-1}$

- 240 ng.mL $L^{-1}-280$ ng.mL $L^{-1}-320$ ng.mL $L^{-1}-360$ ng.mL $L^{-1}-400$ ng.mL $L^{-1}$

Wavelength (nm) 
(C) Fenamiphos (FP)

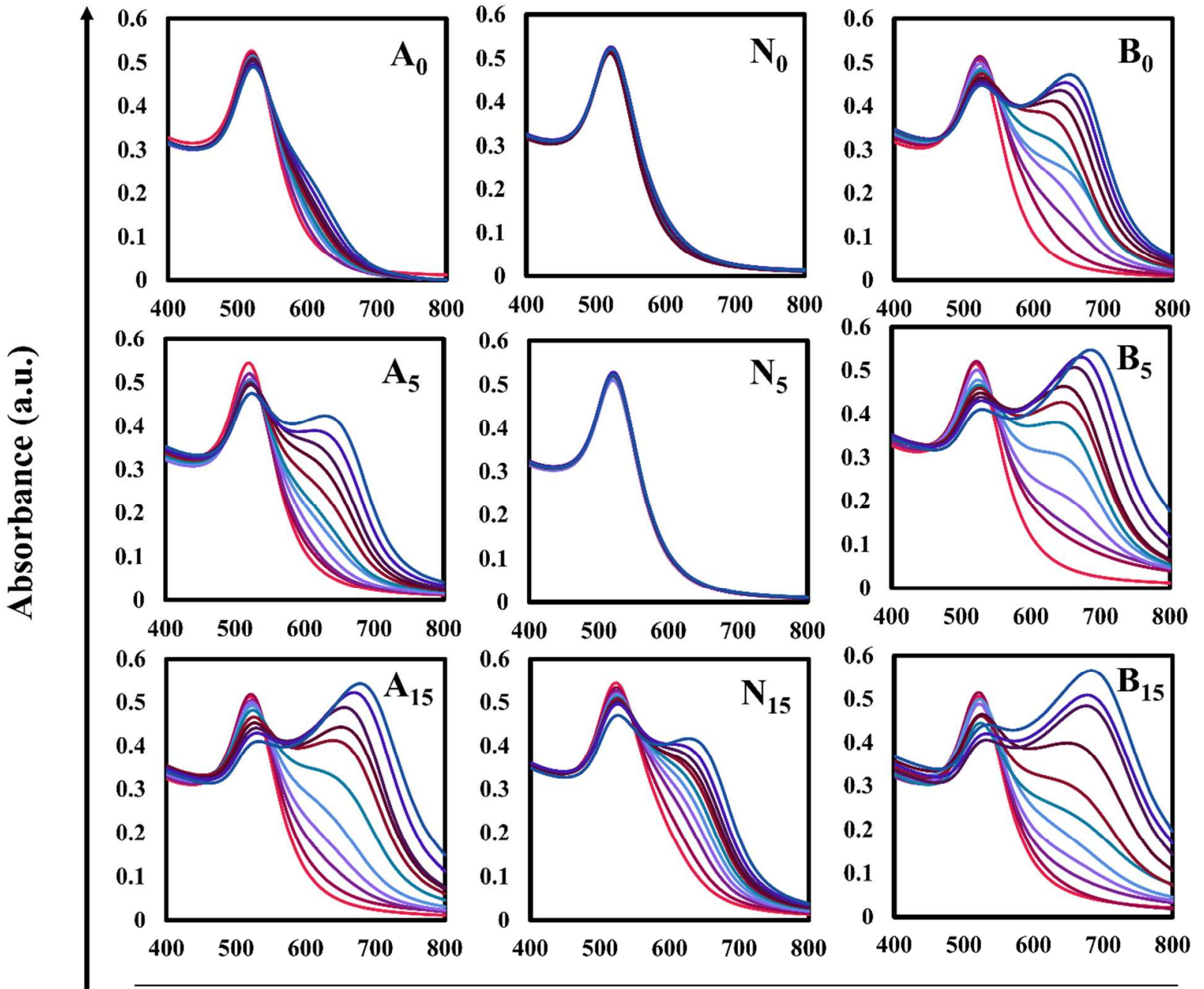

- Blank

-40 ng.mL $L^{-1}-80$ ng.mL $L^{-1}-120$ ng.mL $L^{-1}-160$ ng.mL $L^{-1}-200$ ng.mL $L^{-1}$

- 240 ng.mL $L^{-1}-280$ ng.mL $L^{-1}-320$ ng.mL $L^{-1}-360$ ng.mL $L^{-1}-400$ ng.mL $L^{-1}$

\section{Wavelength (nm)}


(D) Pirimiphos-methyl (PM)

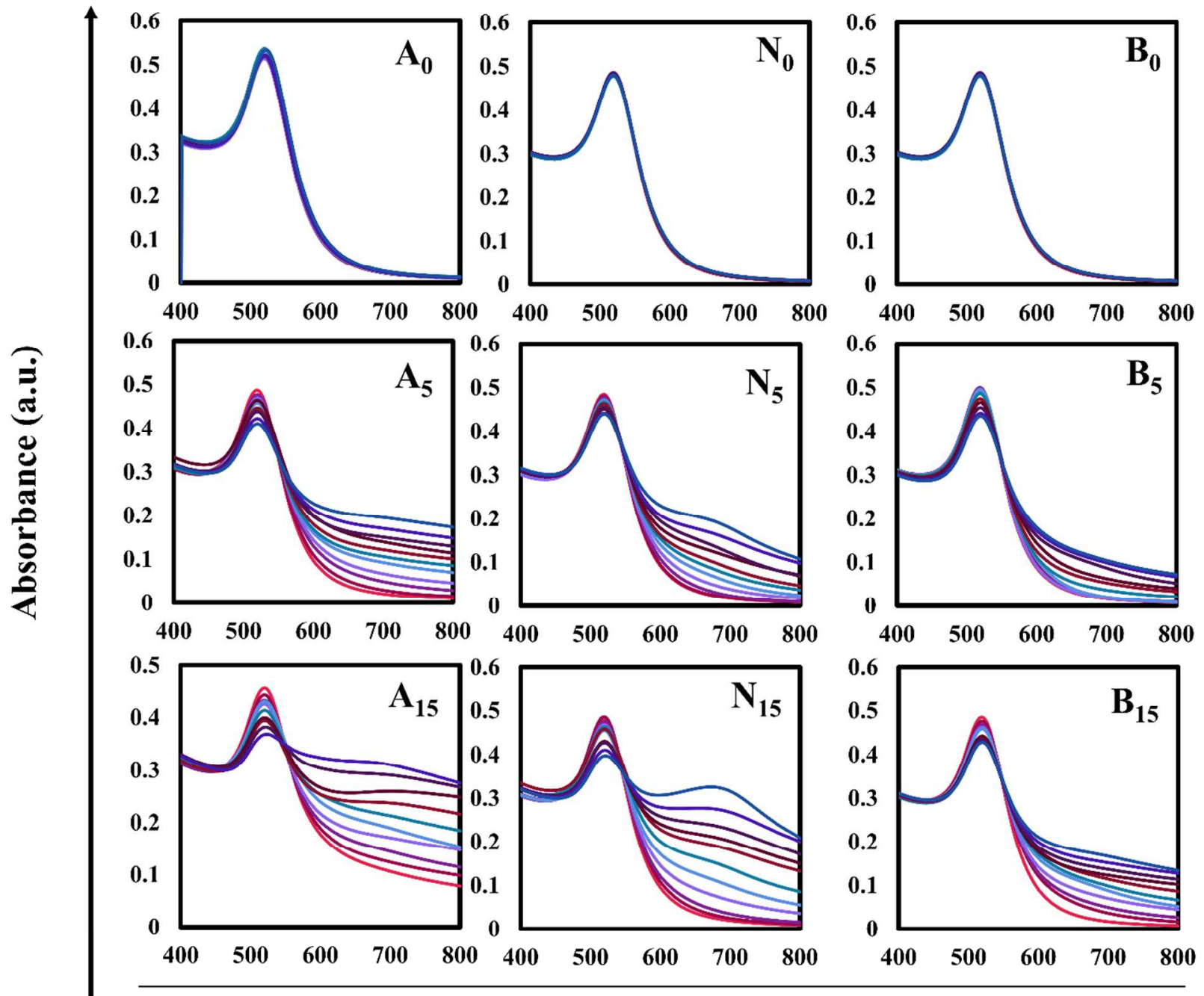

— Blank

- 40 ng.mL $L^{-1}-80 \mathrm{ng} \cdot \mathrm{mL}^{-1}-120 \mathrm{ng} \cdot \mathrm{mL}^{-1}-160 \mathrm{ng} \cdot \mathrm{mL}^{-1}-200 \mathrm{ng} \cdot \mathrm{mL}^{-1}$

- 240 ng.mL $L^{-1}-280$ ng.mL $L^{-1}-320$ ng.mL $L^{-1}-360$ ng.mL $L^{-1}-400$ ng.mL $L^{-1}$

Wavelength (nm) 
(E) Phosalone (PS)

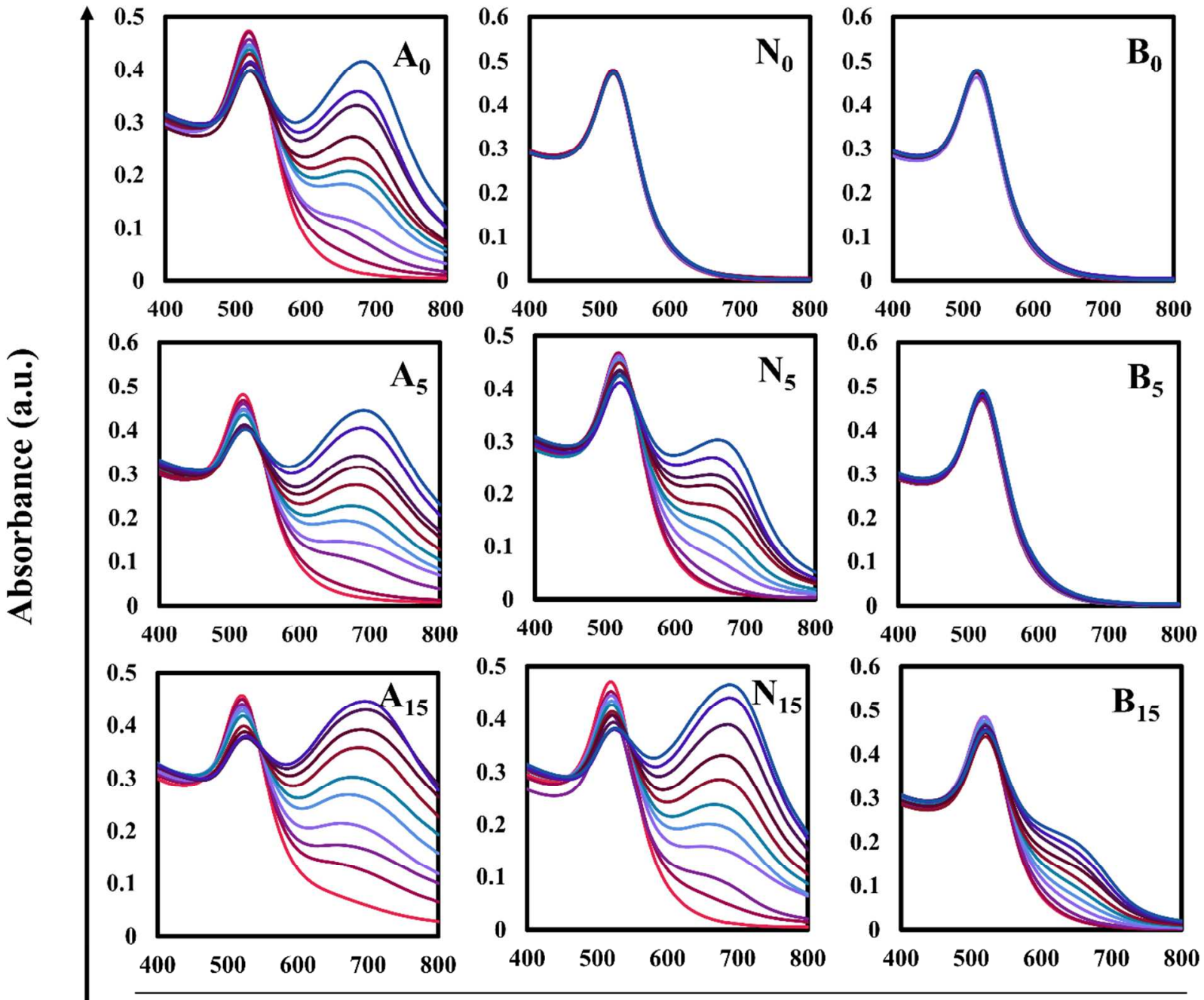

- Blank

- 40 ng.mL $L^{-1}-80$ ng.mL $L^{-1}-120$ ng.mL $L^{-1}-160$ ng.mL $L^{-1}-200$ ng.mL $L^{-1}$

- 240 ng.mL $L^{-1}-280$ ng.mL $L^{-1}-320$ ng.mL $L^{-1}-360$ ng.mL $L^{-1}-400$ ng.mL $L^{-1}$

\section{Wavelength (nm)}

Figure S3 Absorbance spectra of citrate coated AuNPs at different ionic strengths/pHs before and after exposure to (A) Azinphos-methyl (AM), (B) Chlorpyrifos (CP), (C) Fenamiphos (FP), (D) Pirimiphos-methyl (PM) and (E) Phosalone (PS) at various concentrations ranging from 40-400 ng. $\mathrm{mL}^{-1}$. All the experiments were done in triplicate. (A refers to sensing elements at Acidic condition $(\mathrm{pH}=4.5), \mathbf{N}$ refers to neutral condition $(\mathrm{pH}=6.5)$ and $\mathbf{B}$ refers to basic condition $(\mathrm{pH}=9.0)$ of sensing elements. Furthermore 0,5 and 15 are representative of different concentrations of $\mathrm{NaCl}$.) 
Figure S4

(A)
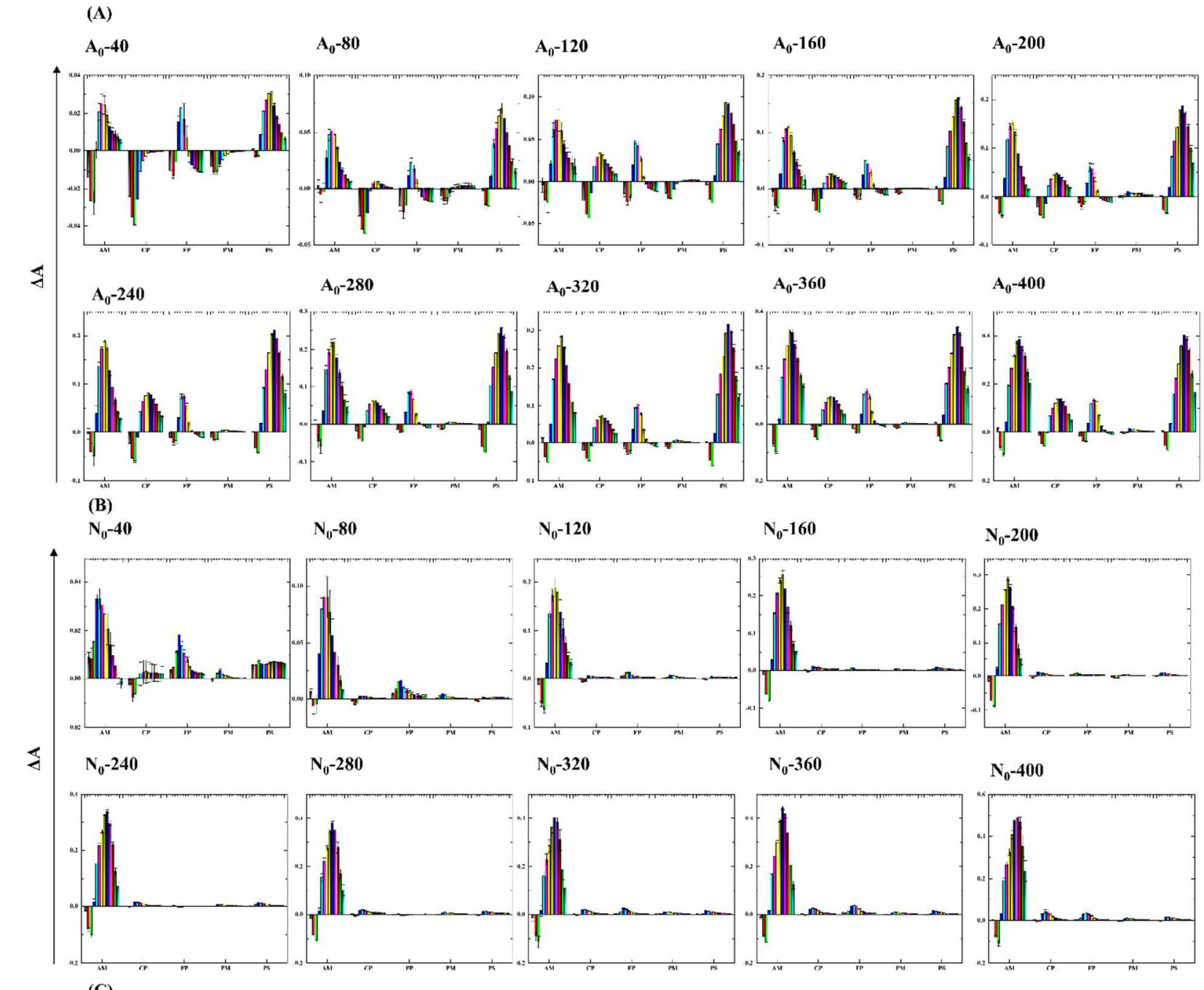

$\mathrm{N}_{0}-\mathbf{2 0 0}$

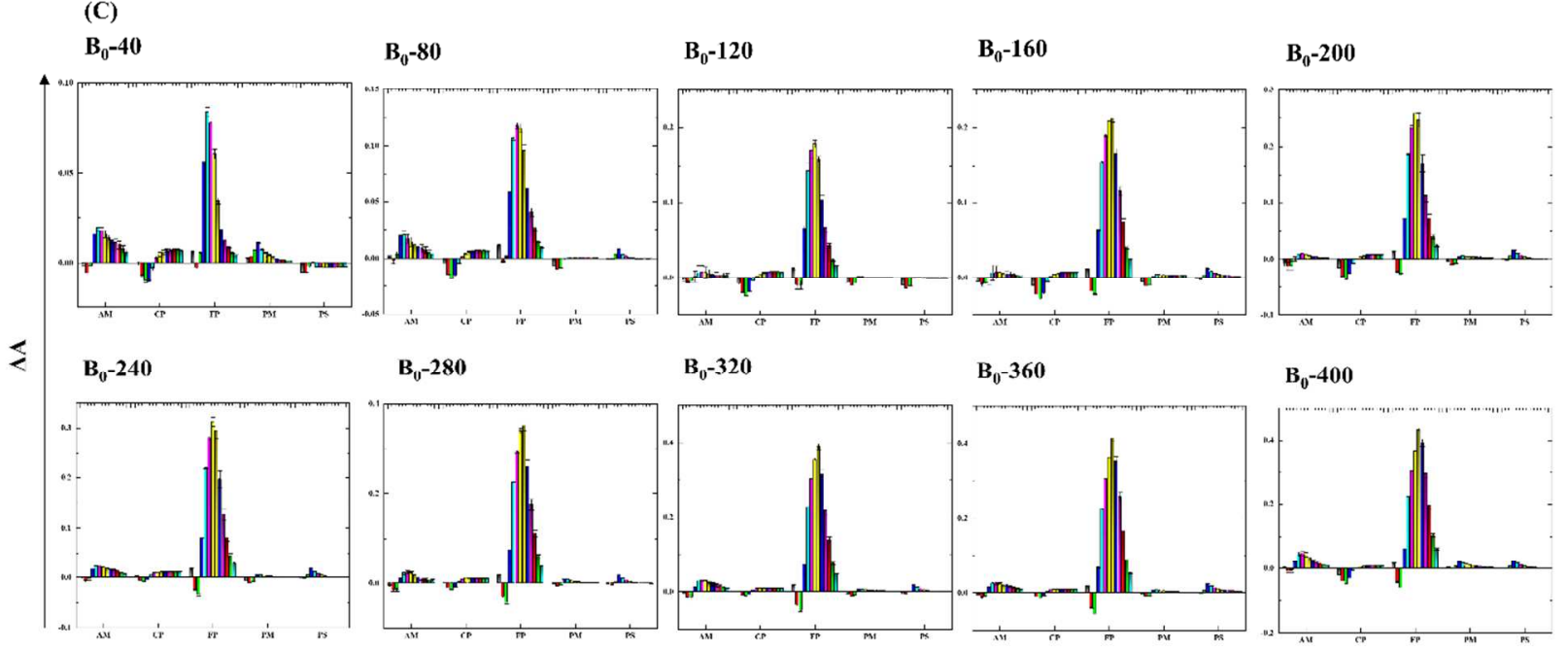


Figure S4- (continue)

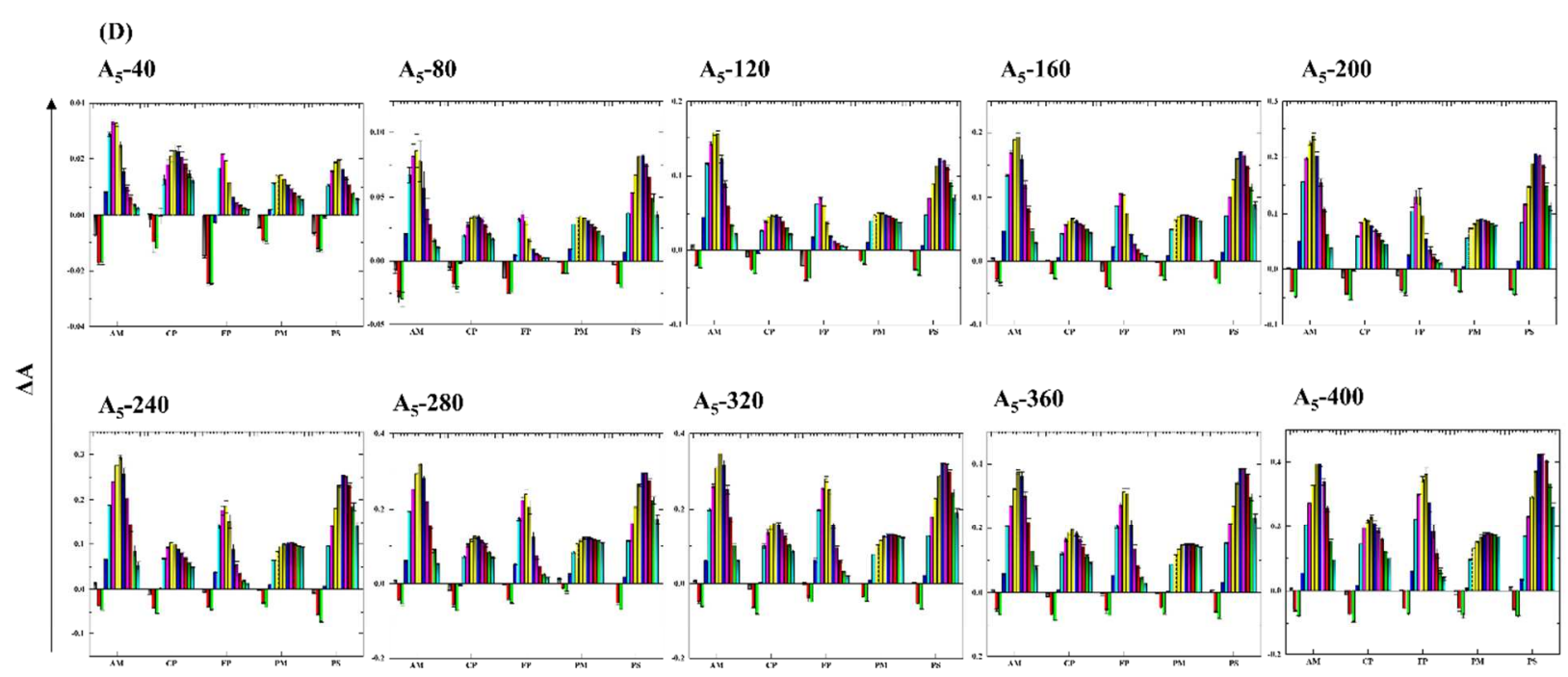

$$
\text { (E) }
$$

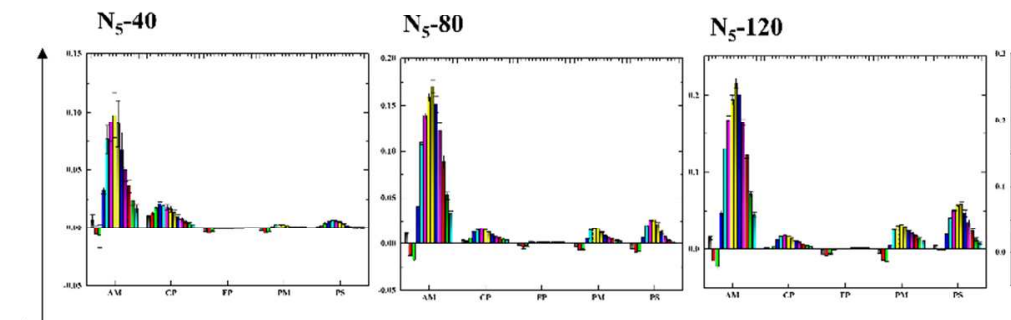

$j$

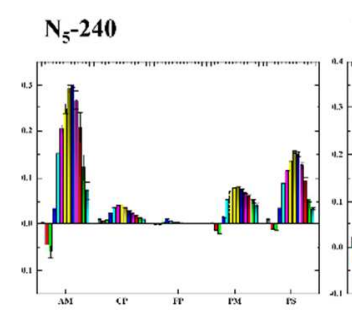

$$
\mathrm{N}_{5}-\mathbf{2 8 0}
$$

$\mathrm{N}_{5}-320$

$\mathrm{N}_{5}-160$

$\mathrm{N}_{5}-\mathbf{2 0 0}$

(F)

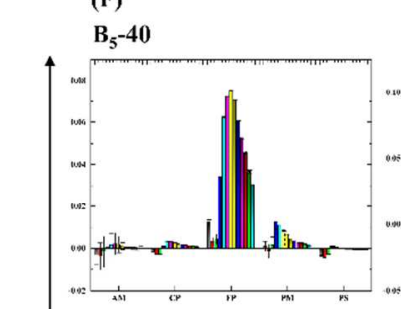

$B_{5}-80$

$B_{5}-120$

$B_{5}-160$

$\mathbf{B}_{5}-\mathbf{2 0 0}$

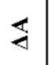
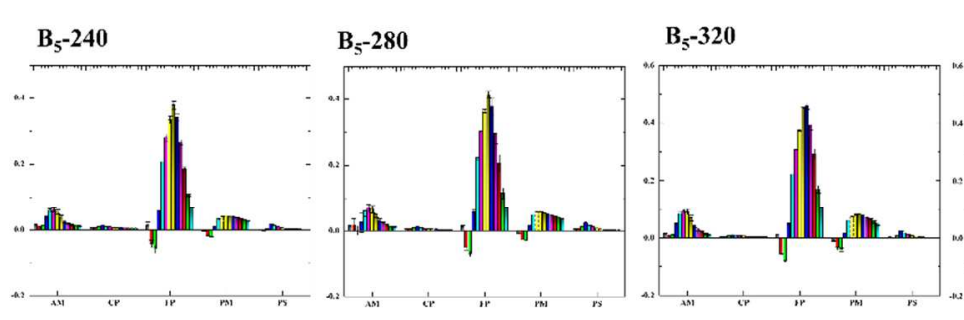

$B_{5}-360$ 
Figure S4- (continue)
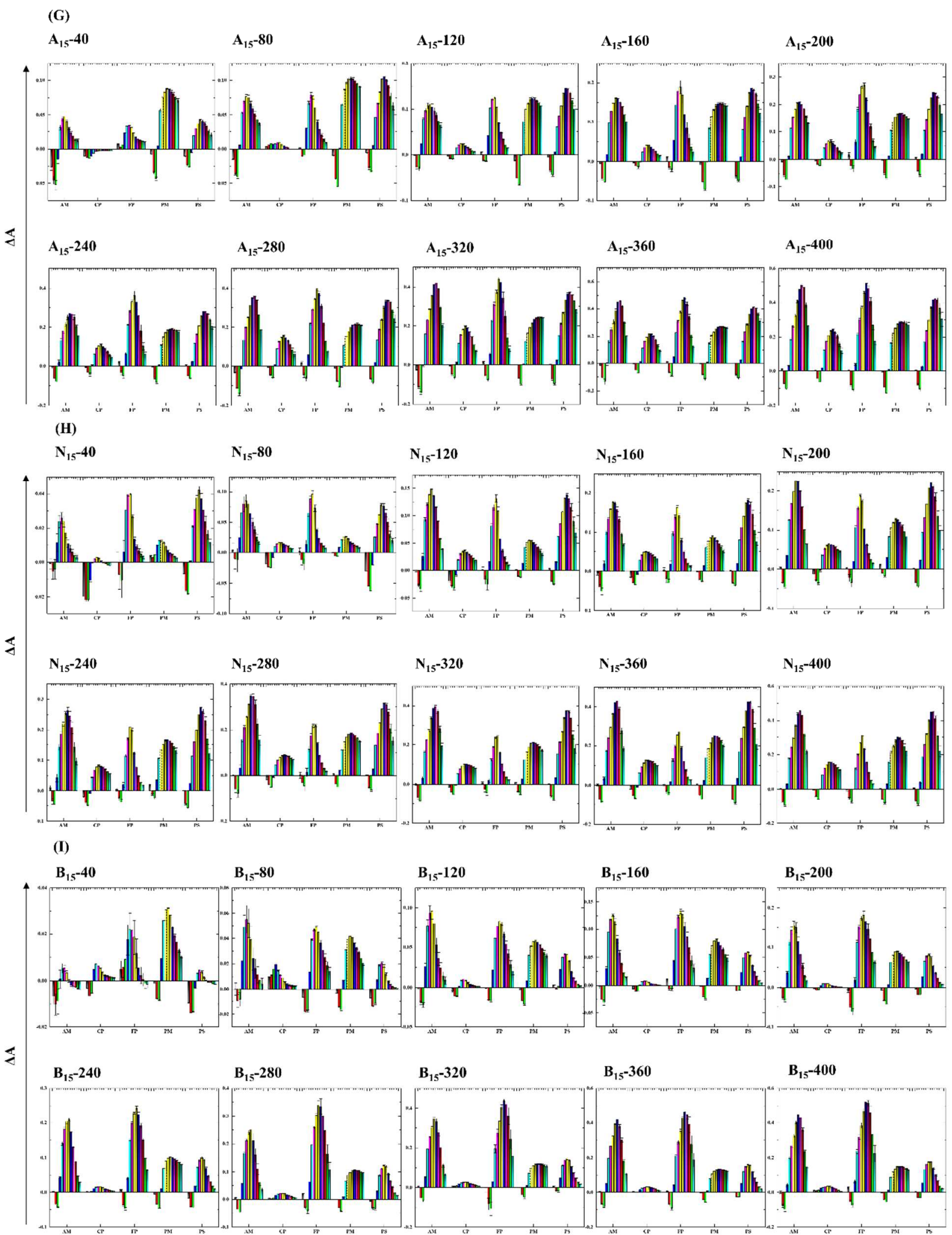
Figure S3 Absorbance response patterns of AuNPs at (A) $\mathrm{pH}=4.5$ and $0 \mathrm{mM} \mathrm{NaCl}(\mathrm{A} 0)$, (B) $\mathrm{pH}=6.5$ and $0 \mathrm{mM}$ $\mathrm{NaCl}(\mathrm{N} 0),(\mathrm{C}) \mathrm{pH}=9.0$ and $0 \mathrm{mM} \mathrm{NaCl}$ (B0), (D) $\mathrm{pH}=4.5$ and $5 \mathrm{mM} \mathrm{NaCl}$ (A5), (E) $\mathrm{pH}=6.5$ and $5 \mathrm{mM} \mathrm{NaCl}(\mathrm{N} 5)$, (F) $\mathrm{pH}=9.0$ and $5 \mathrm{mM} \mathrm{NaCl}(\mathrm{B} 5),(\mathrm{G}) \mathrm{pH}=4.5$ and $15 \mathrm{mM} \mathrm{NaCl}$ (A15), (H) $\mathrm{pH}=6.5$ and $15 \mathrm{mM} \mathrm{NaCl}$ (N15), (I) $\mathrm{pH}=9.0$ and $15 \mathrm{mM} \mathrm{NaCl}$ (B15) against five OPs at concentrations ranging from 40-400 ng. $\mathrm{mL}^{-1}$ at 13 wavelengths of $450,500,520,550,580,600,620,650,680,700,720,750$ and $780 \mathrm{~nm}$. 
Figure S5
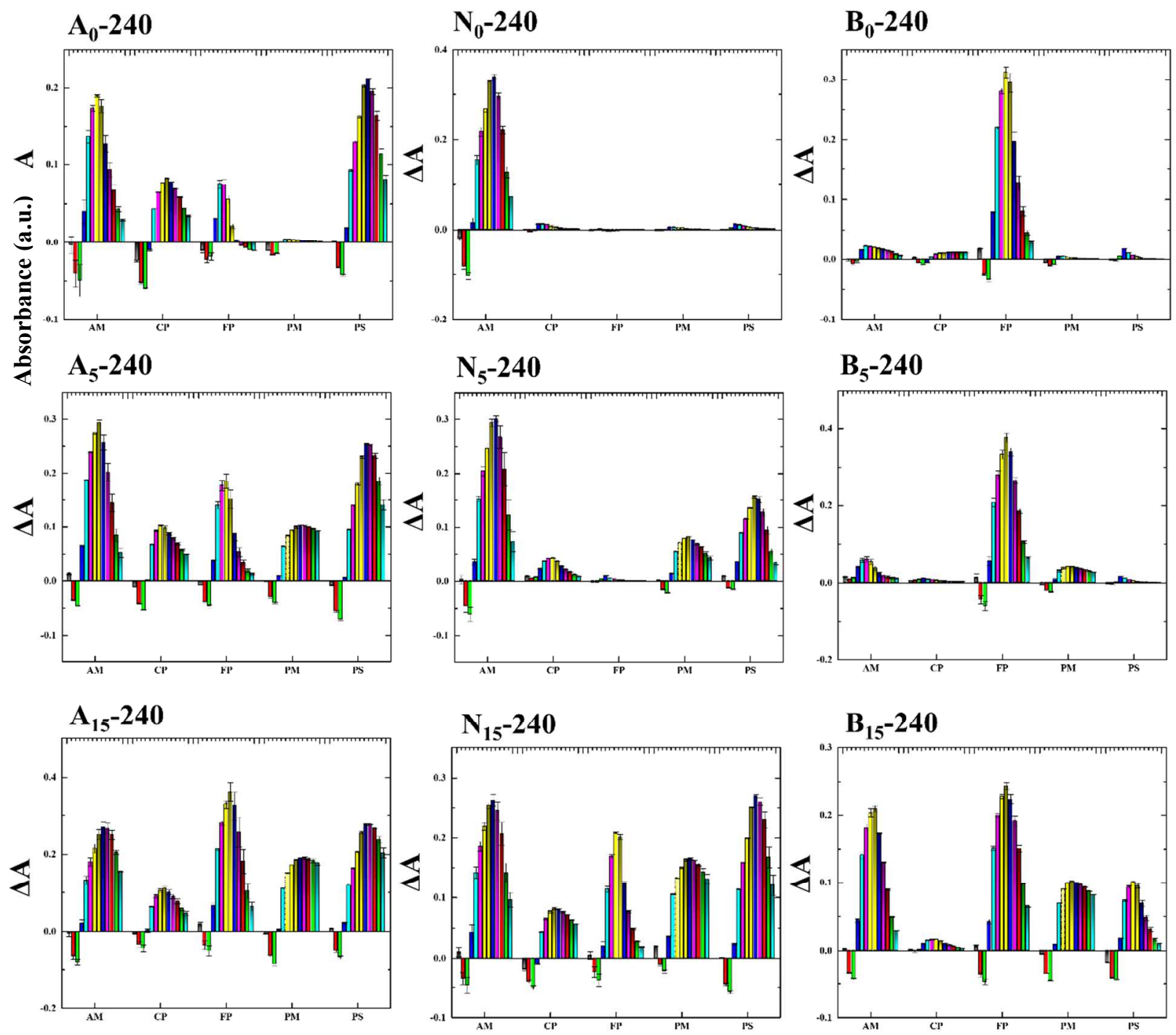

Figure S4 Absorbance response pattern of AuNPs at various pHs/ionic strengths, as sensing elements, against five OPs at concentration of $240 \mathrm{ng}$. $\mathrm{mL}^{-1}$ at wavelengths of $450,500,520,550,580,600,620,650,680,700,720,750$ and $780 \mathrm{~nm}$. 
Figure S6
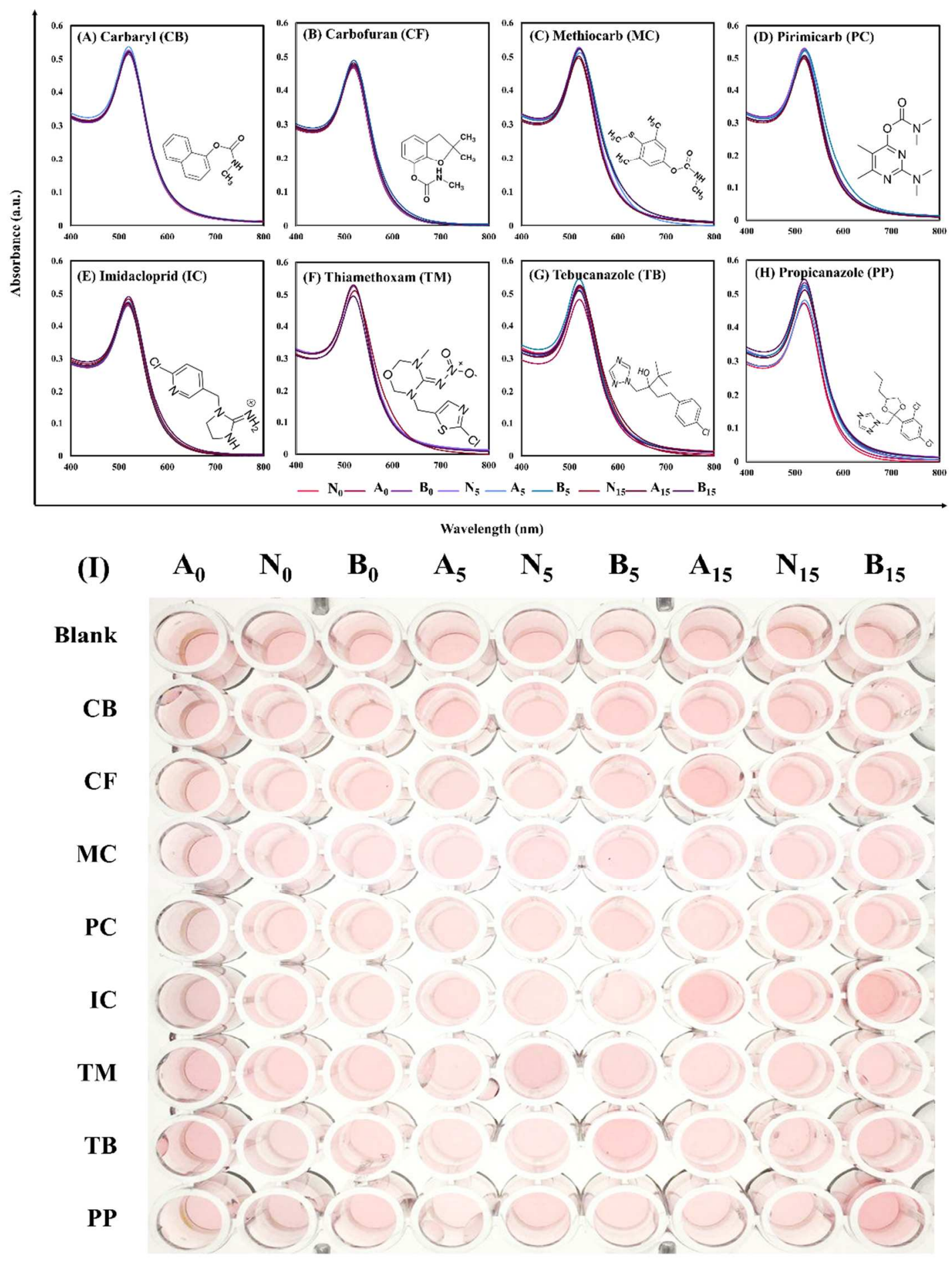

Figure S6 UV-Vis Spectra of AuNPs sensing element before and after exposure to (A) carbaryl (B) carbofuran (C) methiocarb (D) pirimicarb (E) imidacloprid (F) thiamethoxam (G) tebuconazole and (H) propiconazole and (I) their corresponding color change patterns at $4000 \mathrm{ng}$. $\mathrm{mL}^{-1}$ done in triplicate. 


\section{Figure S7}
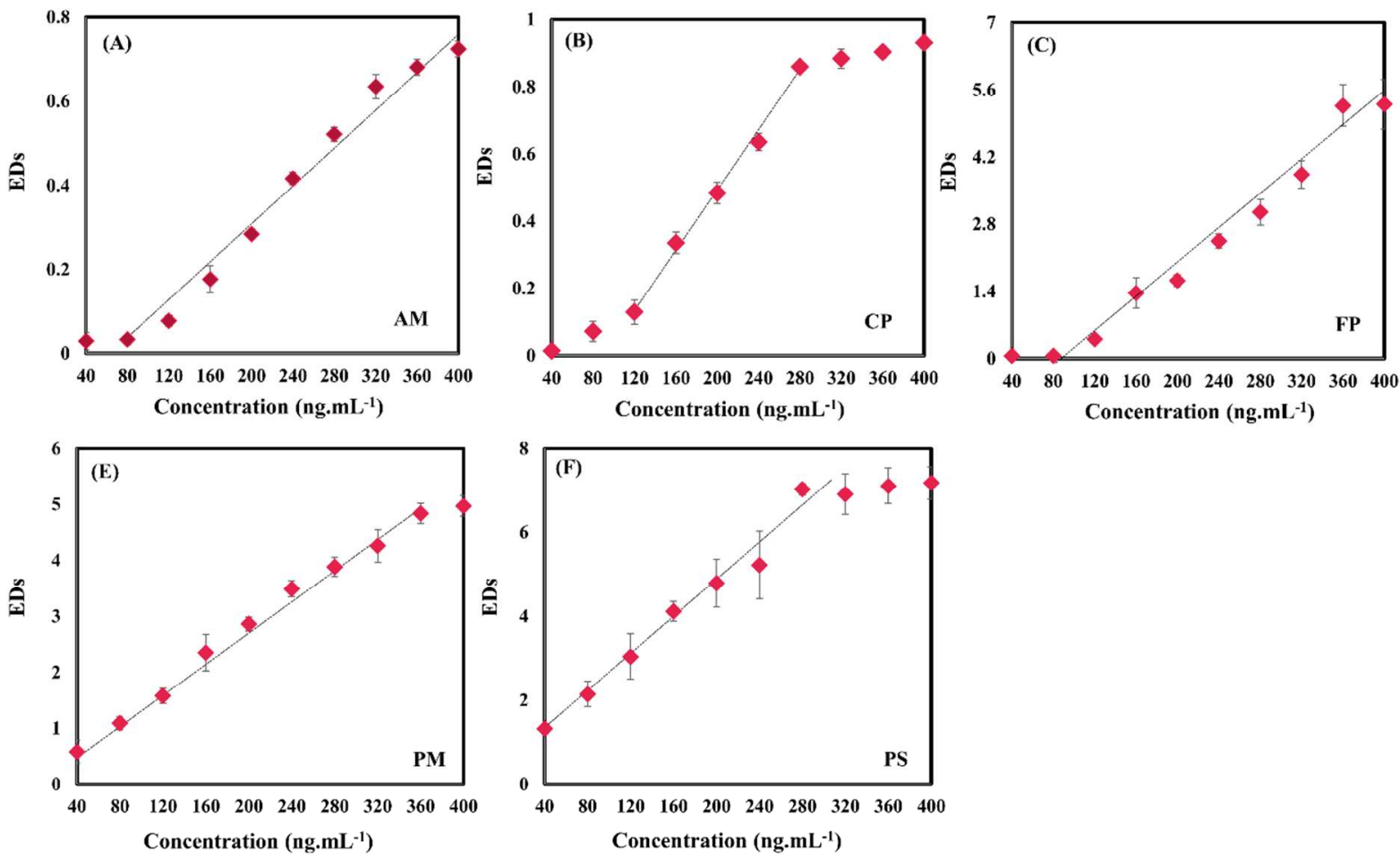

Figure S7 Euclidean distance (ED) of the array color change plotted versus different concentrations of AM, CP, FP, $\mathrm{PF}$ and PS. 
Figure S8
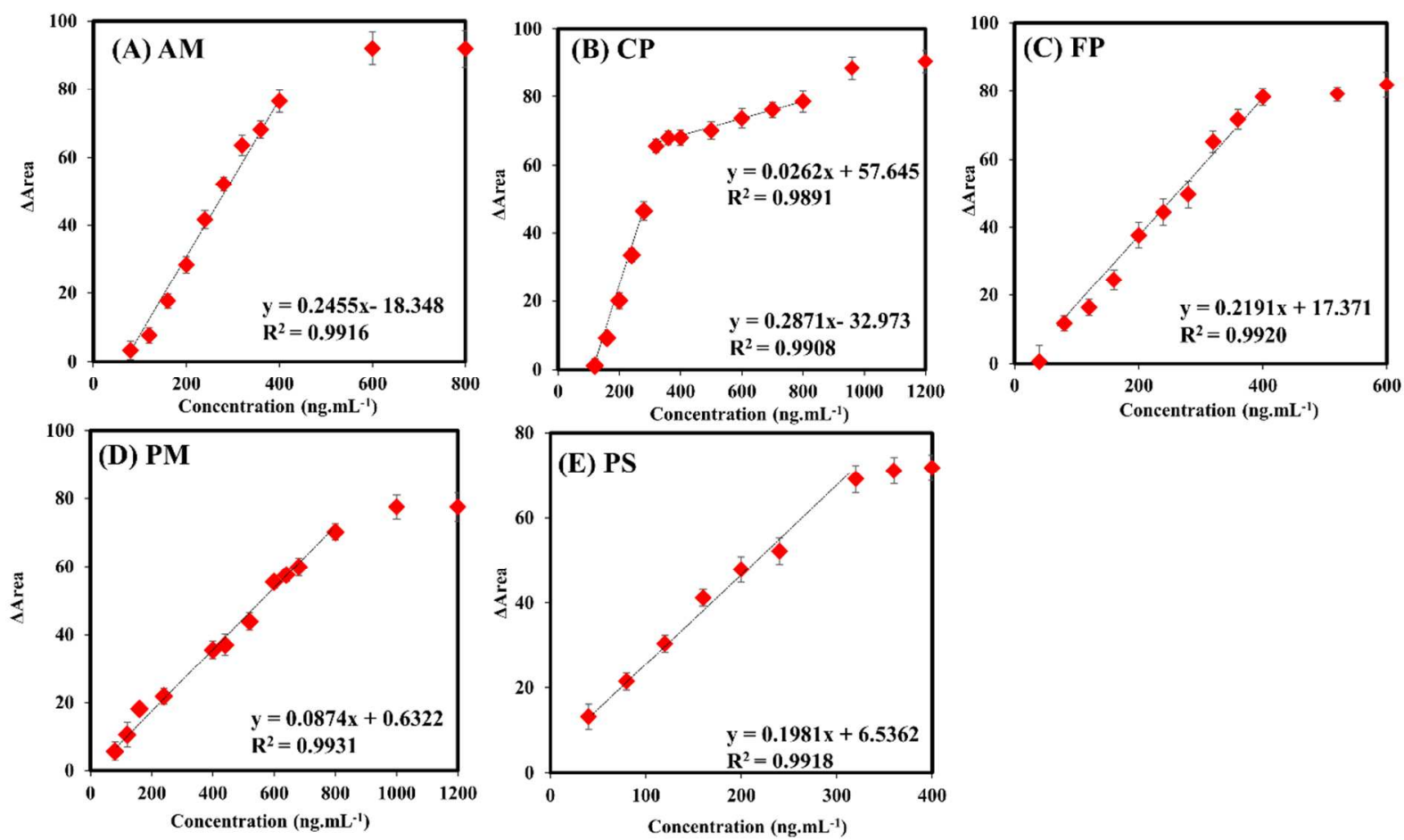

Figure S8 Calibration curves based on the largest response among nine sensor elements for AM, CP, FP, PF and PS. 
Figure S9
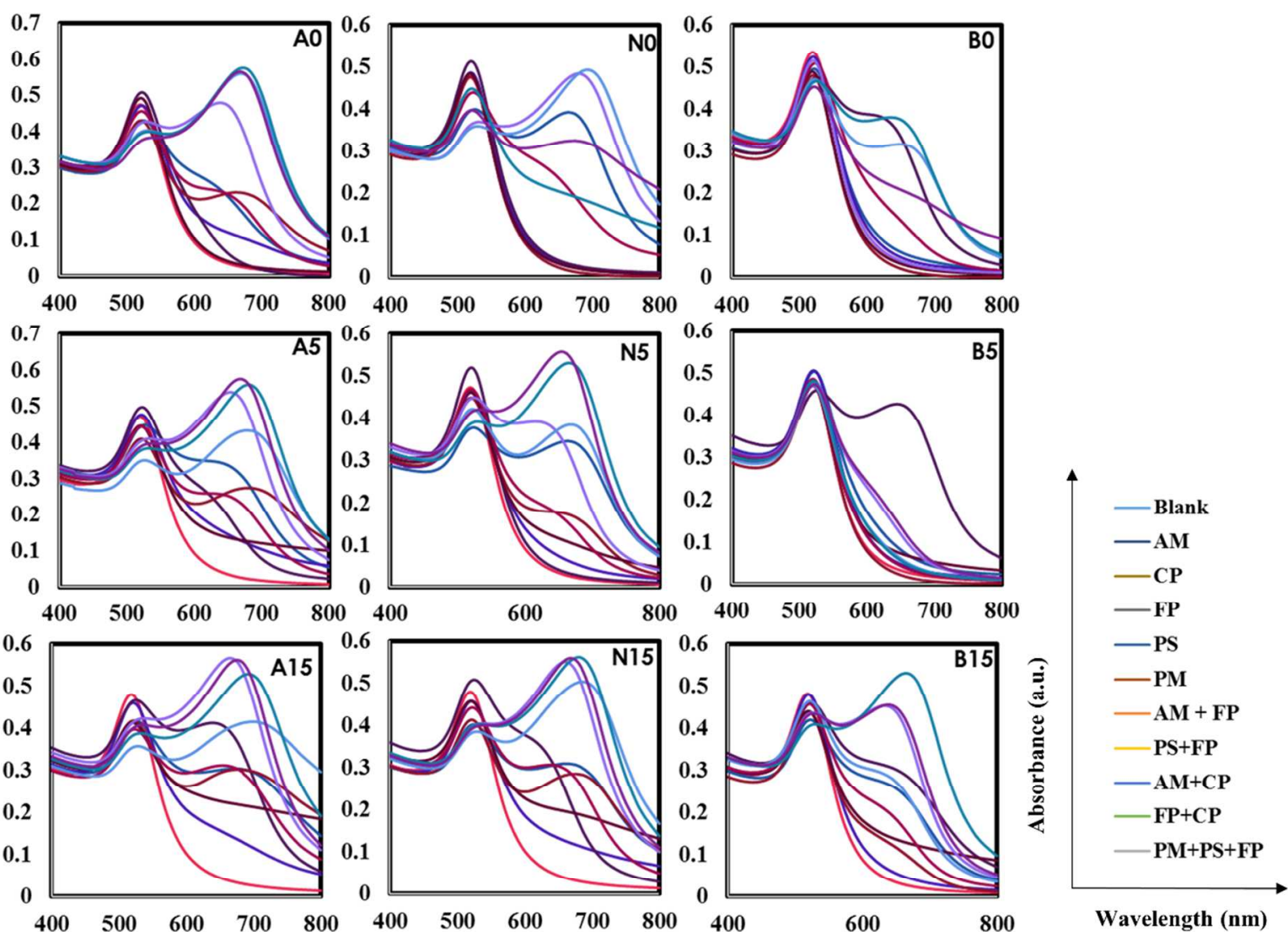

Figure S9 Absorbance spectra of citrate coated AuNPs at different pHs/ionic strengths, as sensing elements, before and after exposure to the AM, CP, FP, PM, PS and their mixtures (at concentration of $240 \mathrm{ng}$. $\mathrm{mL}^{-1}$, done in triplicate). 


\section{Figure S10}

(A) $\mathrm{AM}$
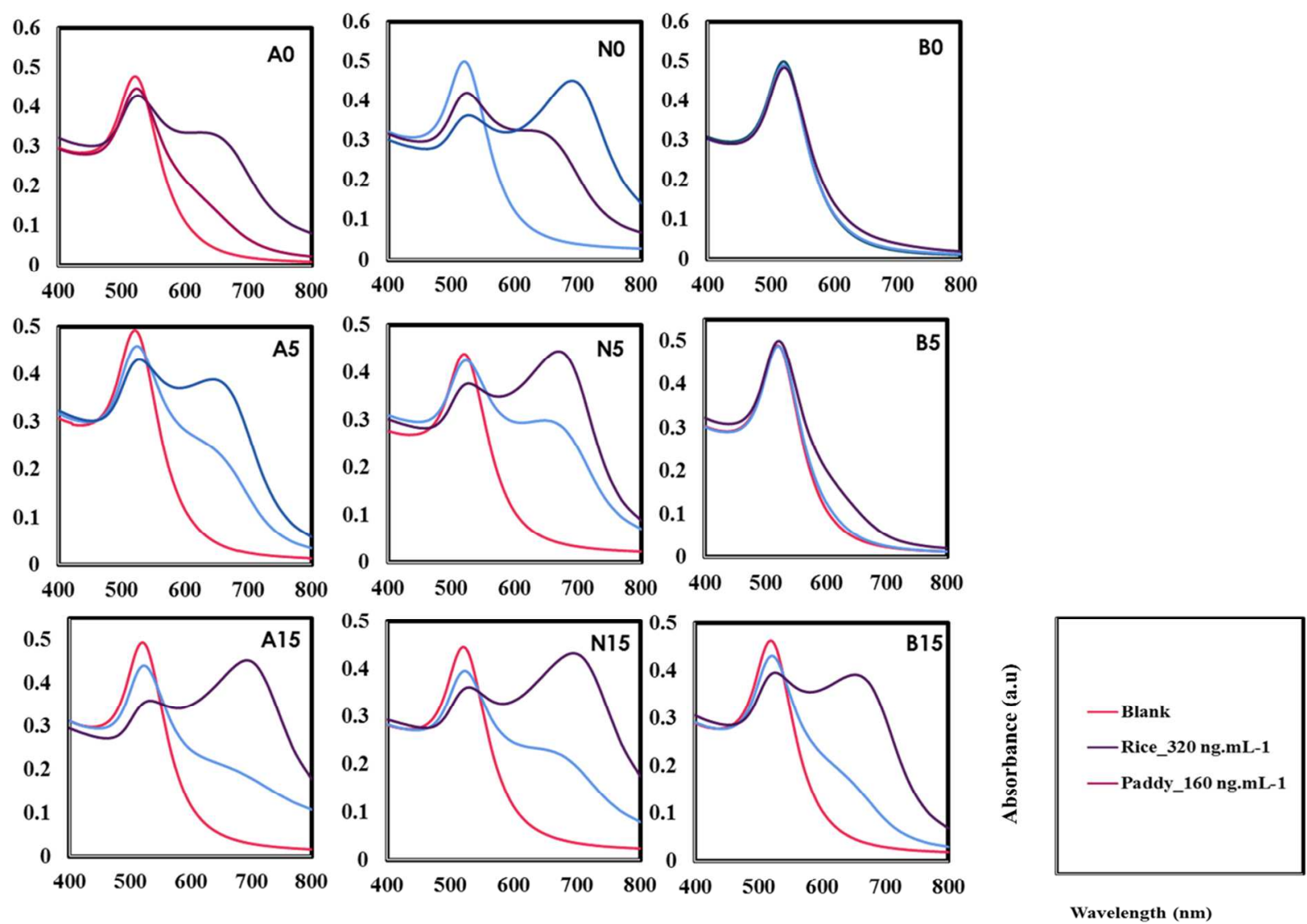
Figure S10- (continue)

(B) $\mathrm{CP}$
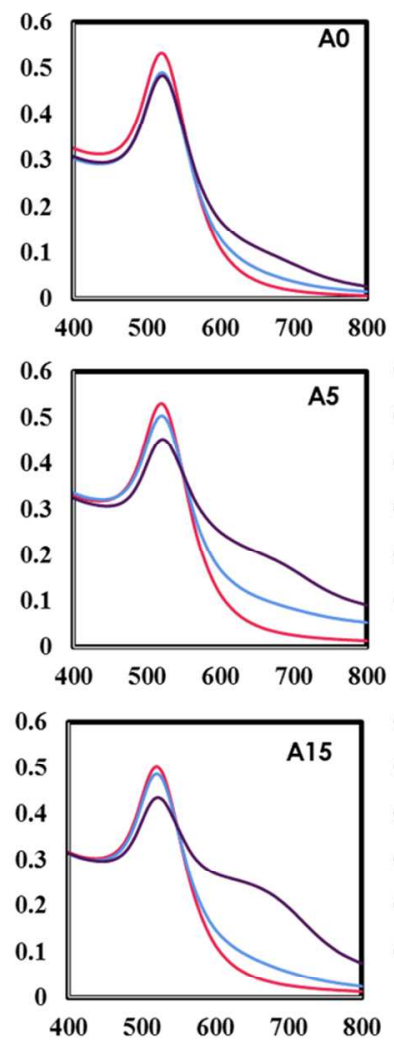
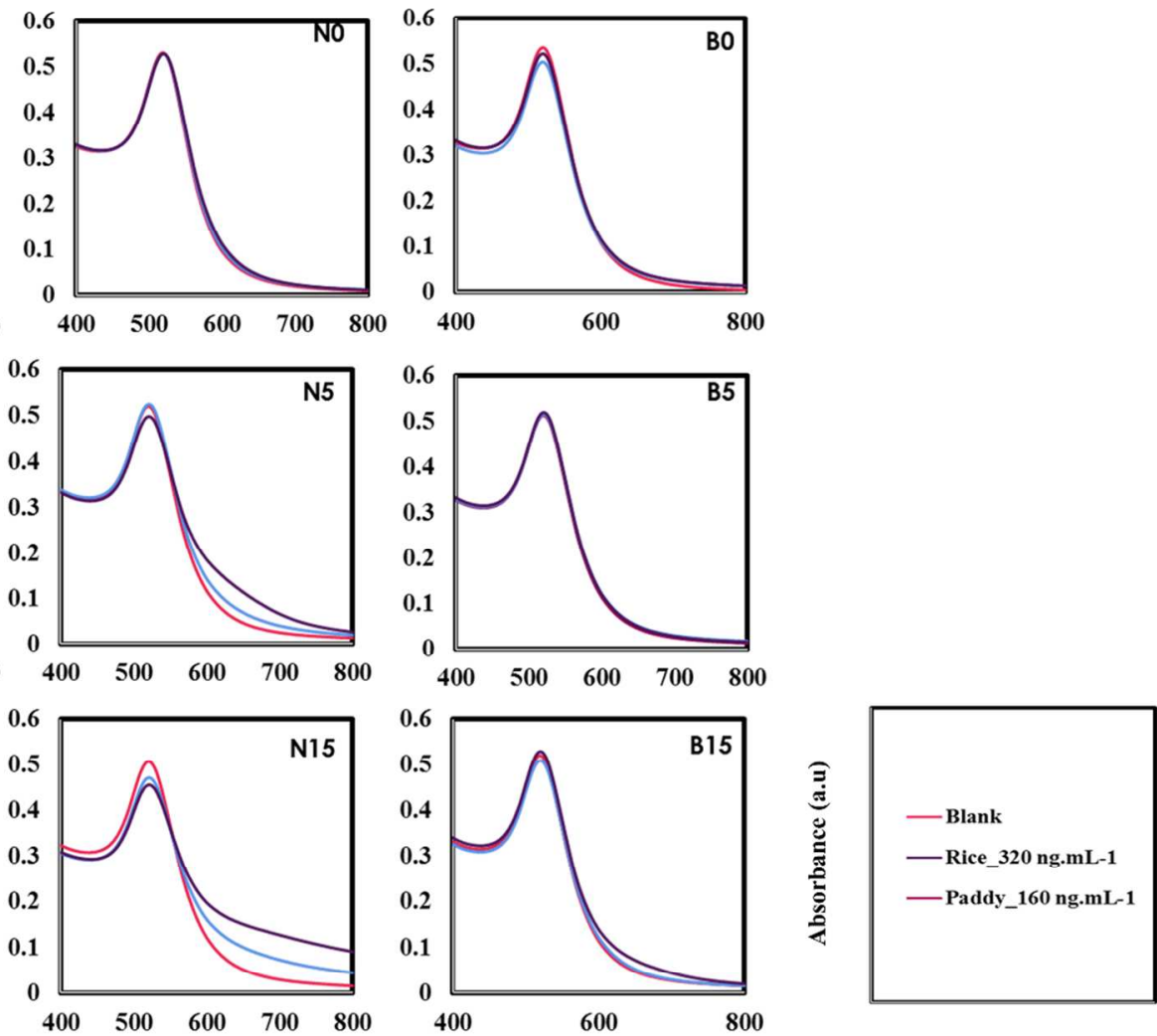

Wavelength (nm) 
Figure S10- (continue)

(C) FP
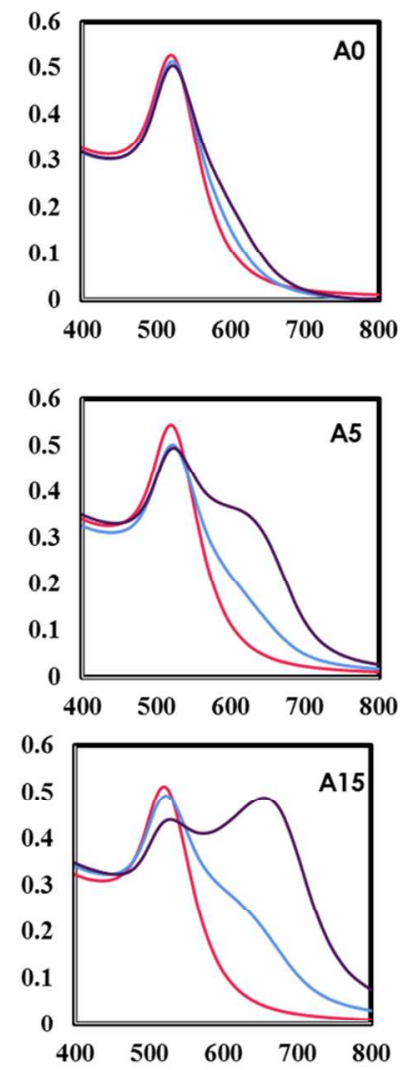
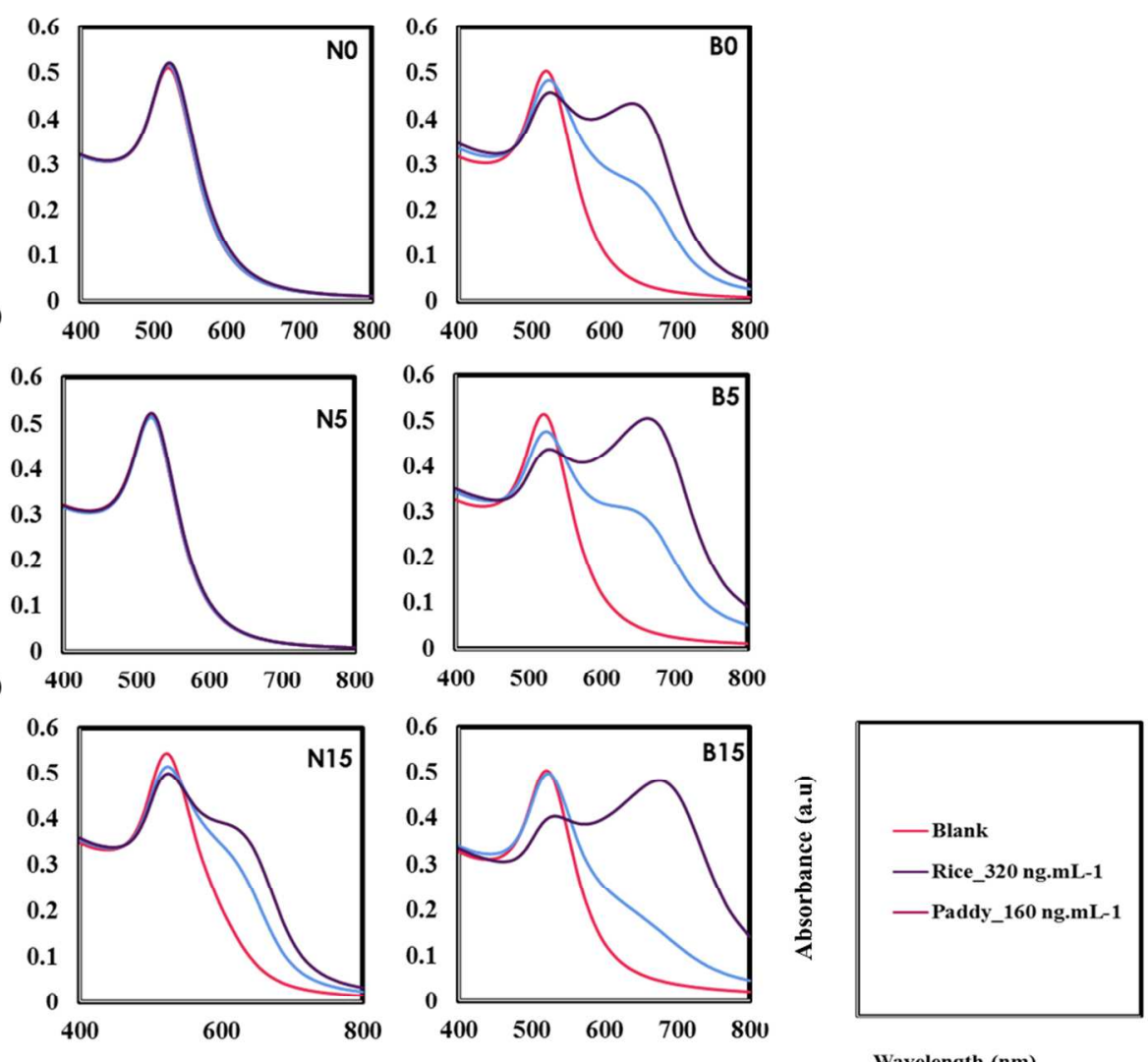
Figure S10- (continue)

(D) PM
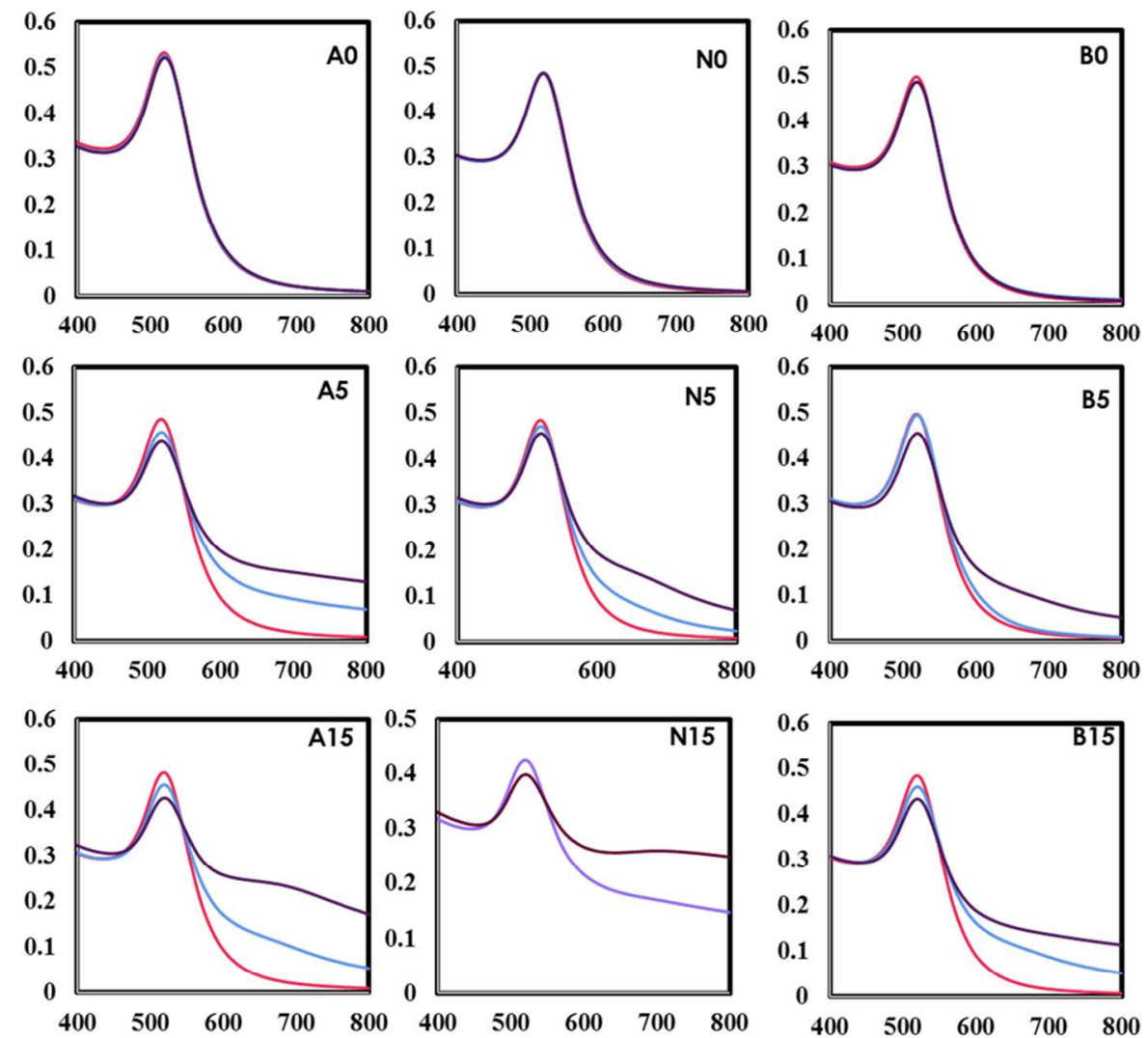
Figure S10- (continue)

(E) PS
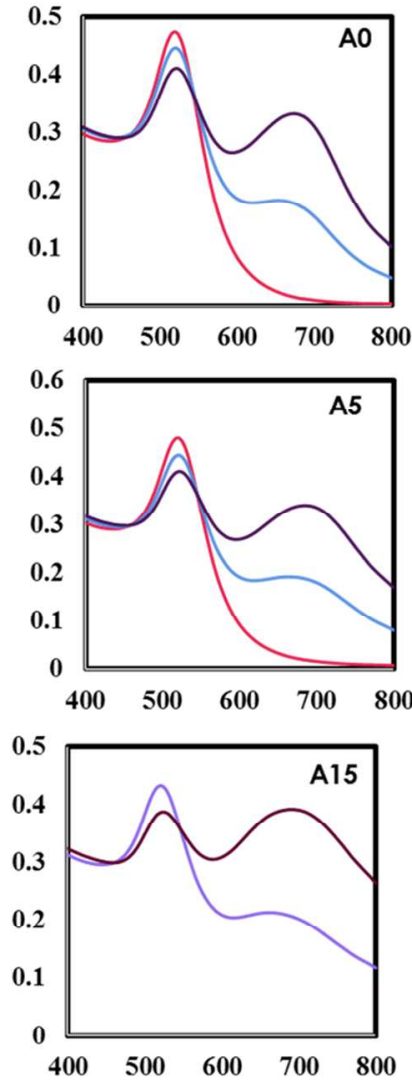
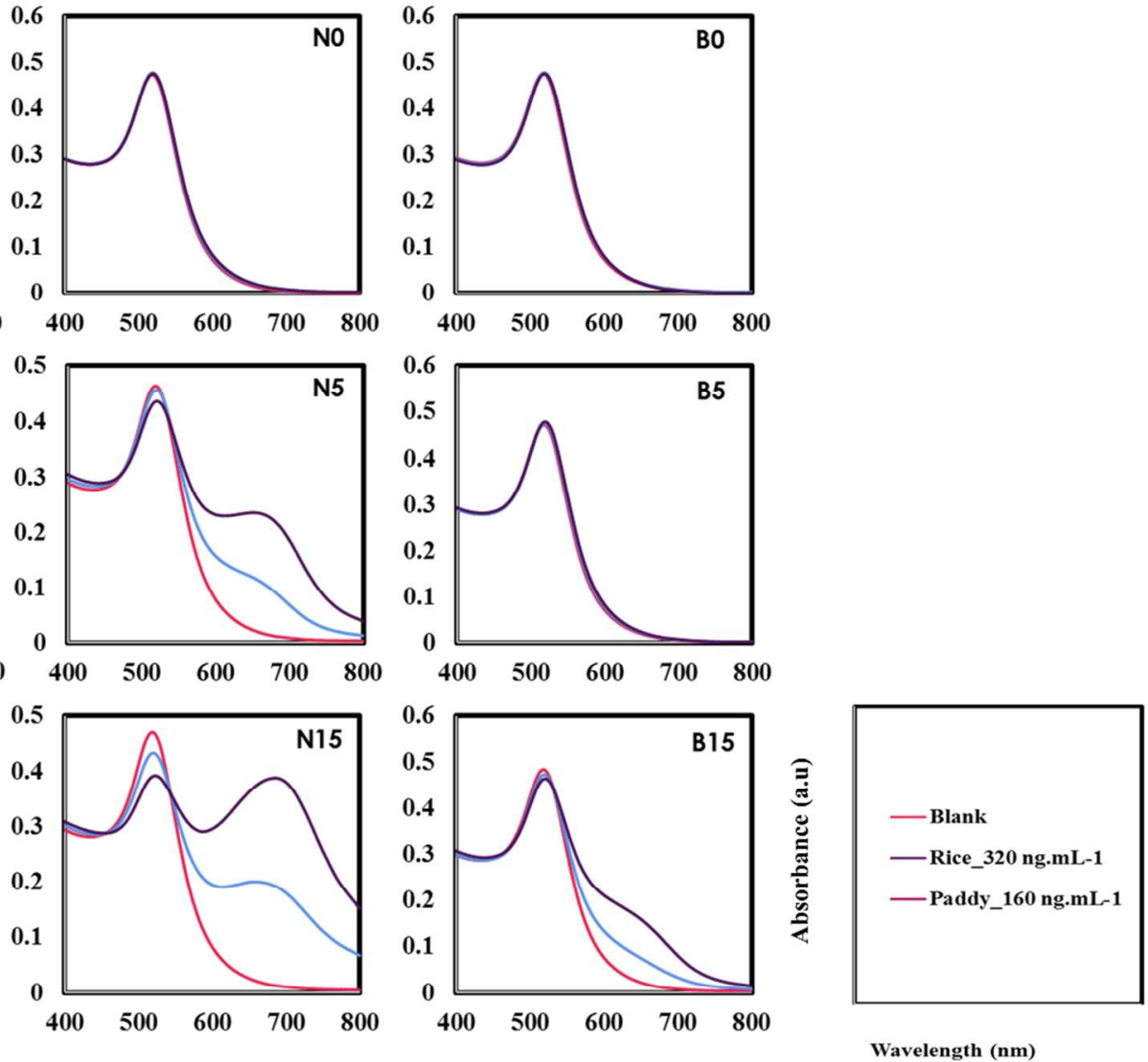

Figure S10 Absorbance spectra of citrate-coated AuNPs at different pHs/ionic strengths, as sensing elements, before and after exposure to rice and paddy water spiked with AM, CP, FP, PM, PS (concentration of 320 and $160 \mathrm{ng}^{\mathrm{mL}} \mathrm{mL}^{-}$ 1 , in presence of $4000 \mathrm{ng}$. $\mathrm{mL}^{-1}$ of other pesticides, done in triplicate). 